\title{
ARYLESTERASE ACTIVITIES IN THE PLASMA OF RATS, RABBITS AND HUMANS ON LOW- AND HIGH-CHOLESTEROL DIETS
}

\author{
A. C. Beynen, ${ }^{*}+\ddagger$ G. J. B. Weinans* and M. B. Katan* \\ *Department of Human Nutrition, Agricultural University, De Dreijen 12, 6703 BC Wageningen, The \\ Netherlands; and $\uparrow$ Department of Laboratory Animal Science, State University, Yalelaan 1, 3508 TD \\ Utrecht, The Netherlands (Tel: 030-532033)
}

(Received 3 January 1984)

\begin{abstract}
Arylesterase activities were measured with $\beta$-naphthylpropionate and/or $\alpha$-naphthylacetate as substrate in the plasma of rats, rabbits and humans on low- and high-cholesterol diets.

2. The plasma esterase activities measured with $\alpha$-naphthylacetate were similar in rats, rabbits and humans. With $\beta$-naphthylpropionate as a substrate, rabbits were found to have a markedly higher esterase activity than rats and humans.

3. Basal plasma esterase activity was significantly higher in an inbred rat strain which is hyporesponsive to dietary cholesterol than in a hyperresponsive strain.

4. In rats, but not in humans and rabbits, plasma esterase activity was significantly increased by a high-cholesterol diet.

5. In individual humans and random-bred rabbits and rats there was no association between initial plasma total esterase activity and the subsequent plasma cholesterol response to cholesterol feeding.

6 . We suggest that arylesterases are associated with cholesterol metabolism and with the response to dietary cholesterol in rats; evidence for such a role in rabbits and humans is, however, inconclusive.
\end{abstract}

\section{INTRODUCTION}

The plasmata of various vertebrates contain a number of different arylesterases (Augustinsson, 1958) which are defined by their capability to hydrolyse artificial fatty acid esters of aromatic alcohols. In human serum at least 13 (Pilz, 1964) and in rabbit serum (Pilz et al., 1968) 12 different arylesterases have been identified. The enzymes have $\mathrm{pH}$ optima ranging from 7 to 9.5 and differ in substrate specificity, including the chain length of the esterified fatty acid. The genetics of serum esterases in the rat have been described in detail (Van Zutphen, 1983).

The physiological function of the arylesterases is obscure. It has been suggested (Pilz et al., 1966; Pilz, 1968) that they catalyse the covalent coupling of fatty acids to tyrosine groups in plasma albumin. Plasma esterases may also be involved in cholesterol metabolism. In inbred strains of rabbits (Van Zutphen and Fox, 1977) and rats (Okamoto et al., 1972; Van Zutphen and Den Bierman, 1981) it was found that variation in the response of plasma cholesterol level to dietary cholesterol was associated with a genetically determined variation in plasma esterases. A fast moving esterase zone was present in the plasma zymogram of hyporesponsive strains, but not in that of hyperresponsive strains.

The esterase pattern after gel electrophoresis (Van Zutphen and Fox, 1977; Van Zutphen and Den Bieman, 1981) only gives qualitative information. Therefore, the present study was carried out in an attempt to correlate absolute levels of plasma total

$\ddagger$ Correspondence to be addressed to: Dr. A. C. Beynen, Department of Laboratory Animal Science, State University, Yalelaan 1, 3508 TD Utrecht, The Netherlands. esterase activities and the serum cholesterol responses to dietary cholesterol in rats, rabbits and humans. In addition, the effect of a high-cholesterol diet on plasma total esterase activity was measured. Part of this work has appeared in abstract form (Beynen et al., 1983).

\section{MATERIALS AND METHODS}

\section{Analytical methods}

Plasma esterase activities were determined at $\mathrm{pH} 8.6$ using $\alpha$-naphthylacetate (Merck, Darmstadt, FRG) or $\beta$-naphthylpropionate (Sigma Chemical Co., St. Louis, MO, USA) as a substrate according to Pilz and Johann (1965) and Pilz (1961), respectively. Reaction conditions were chosen so that enzyme activity was proportional to time and enzyme concentration. Enzyme activity was corrected for spontaneous hydrolysis of the substrate. Plasma samples were stored at $-20^{\circ} \mathrm{C}$ for periods up to 4 weeks until analysis. All samples of one experiment were analysed within one batch. Reproducibility (coefficient of variation) was routinely less than $1.5 \%$.

Rat plasma esterase phenotypes were determined by starch gel electrophoresis (pH 8.75) and staining with Fast Blue BB (Merck, Darmstadt, FRG) and with $\beta$-naphthylpropionate ( $\mathrm{pH} 7.3$ ) as substrate (Okamoto et al., 1972).

Plasma total cholesterol was measured enzymatically according to Röschlau et al. (1974) using the kit (Monotest) supplied by Boehringer-Mannheim GmbH, FRG.

\section{Experiments with rats}

Male rats of two fully inbred strains and male and female random-bred Wistar rats were used. The inbred strains, $\mathrm{SD} / \mathrm{Cpb}$ and $\mathrm{SHR} / \mathrm{Cpb}$, were purchased at the age of about 3 weeks from the Central Institute for the Breeding of Laboratory Animals (CPB-TNO), Zeist, The Netherlands. The strains had previously been shown to be hypo- and hyperresponsive to dietary cholesterol (Van Zutphen and 
Den Bieman, 1981). The Wistar rats were maintained at the Small Animal Centre (CKP) of the Agricultural University.

The inbred and random-bred rats were fed a commercial rat diet (Hope Farms, Woerden, The Netherlands) for 3 and 10 weeks, respectively; they were then divided into an experimental and a control group so that both groups had similar mean body weights and serum cholesterol concentrations. The control animals remained on the lowcholesterol, commercial diet, whereas the other animals were transferred to the high-cholesterol diet. The highcholesterol diet consisted of $92.5 \%(\mathrm{w} / \mathrm{w})$ commercial diet, $5 \%$ olive oil (Puget, Marseille, France), $2 \%$ cholesterol (Duphar BV, Veenendaal, The Netherlands) and $0.5 \%$ sodium cholate (Merck, Darmstadt, FRG).

Blood samples were taken after a 24 -hr fast before and at the end of the experimental period. The samples were drawn into heparinized tubes by orbital puncture under anesthesia with diethyl ether. Plasma was collected by low speed centrifugation.

\section{Experiment with rabbits}

Female random-bred rabbits of the New Zealand White strain were obtained from the Broekman Institute, Helmond, The Netherlands. The rabbits, aged about 11 weeks, were fed a cholesterol-free, semipurified diet for 4 weeks. Then, 9 animals were allocated to a high-cholesterol, semipurified diet, while 7 other rabbits remained on the cholesterol-free control diet. The composition of the semipurified diets was as follows $(\mathrm{g} / \mathrm{kg})$ : soybean protein isolate, 208; methionine, 2; corn starch, 170; dextrose, 210; molasses, 50; coconut fat, 90; soybean oil, 10; cholesterol, 0 (in the high-cholesterol diet, 2); sawdust, 180 (in the high-cholesterol diet, 178); dicalcium phosphate, 29; sodium chloride, 6; magnesium carbonate, 3 ; magnesium oxide, 2; potassium bicarbonate, 18 ; vitamin premix, 12 ; mineral premix, 10 . The composition of the vitamin and mineral premixes have been described (West et al., 1982).

Blood samples were taken from a marginal ear vein between 8 and $10 \mathrm{am}$, after the removal of any remaining food at $4 \mathrm{pm}$ the previous day.

\section{Experiment with humans}

Five healthy subjects (three men and two women, aged 21-36 yr), including G.J.B.W., participated in the experiment. During the study the subjects consumed their habitual diets, with the exception that during the first 10 days cholesterol-rich products were forbidden; during the second 10 days of the study the subjects daily added six egg yolks (equivalent to about $1500 \mathrm{mg}$ of cholesterol) to their diet. During the low-cholesterol period the subjects were asked not to eat eggs or egg-containing products, shell fish, organ meats and butter, and to limit their intake of meat and fish to $100 \mathrm{~g} /$ day. In our experience such a diet results in a cholesterol intake of about $200 \mathrm{mg} /$ day. At the end of this period body weight of the subjects was $69.5 \pm 9.8 \mathrm{~kg}$ ( \pm SD). During the cholesterol-rich period fresh egg yolks were supplied daily as fried or boiled whole eggs, as raw yolks homogenized with orange juice, or worked into salads and desserts. The subjects generally avoided monotony by varying between different items.

Blood was drawn into evacuated, heparinized tubes from an antecubital vein after an overnight fast on the last two days of both the low- and high-cholesterol periods. The mean values of these two days were the initial and final values, respectively.

\section{RESULTS}

Figure 1 shows the zymogram of esterases in plasma from the two inbred rat strains. An anodal fast moving zone, Es-1 esterase (Van Zutphen, 1983) was clearly present in the SHR/Cpb strain, whereas in the $\mathrm{SD} / \mathrm{Cpb}$ strain this zone was absent or stained only very faintly. This difference in zymotype between these rat strains has been reported earlier (Van Zutphen and Den Bieman, 1981). The presence or absence of the Es- 1 esterase often predicts the serum cholesterol response to dietary cholesterol in inbred rat and rabbit strains. The cholesterolemic response was low in 6 out of 7 inbred rat strains displaying the Es- 1 zone, whereas absence of the enzyme was associated with the development of high degrees of hypercholesterolemia after cholesterol feeding in 2 out of 3 inbred rat strains (Van Zutphen and Den Bieman. 1981). Similar results were obtained in a study with six inbred strains of rabbits (Van Zutphen and Fox, 1977) where the cholesterolemic response to dietary cholesterol correlated with the Est-2 genotype. The Est-2 locus of the rabbit is assumed to be homologous with the Es-l locus in the rat (Fox and Van Zutphen, 1979).

Esterase zymograms (cf. Fig. 1) only give qualitative information. Therefore, we addressed the question of whether plasma total esterase activity would be associated with the plasma cholesterol response to dietary cholesterol. At the same time the effect of dietary cholesterol on plasma total esterase activity was investigated.

Table 1 shows that the $\mathrm{SD} / \mathrm{Cpb}$ and $\mathrm{SHR} / \mathrm{Cpb}$ inbred rat strains are indeed hyper- and hyporesponsive to dietary cholesterol. Cholesterol feeding for 23 days induced plasma cholesterol levels of about $8 \mathrm{mmole} / 1$ in the SHR/Cpb strain (hyporesponder) and of about $22 \mathrm{mmole} / \mathrm{l}$ in the $\mathrm{SD} / \mathrm{Cpb}$ strain (hyperresponder). The high-cholesterol diet did not significantly affect body-weight gain of the rats (Table 1).

Plasma esterase activity on the low-cholesterol control diet was significantly lower in the hyperresponsive strain, irrespective of whether $\alpha$-naphthylacetate or $\beta$-naphthylpropionate was the substrate (Table 1). Cholesterol feeding significantly increased plasma esterase activities in both strains, the activity still being higher in the hyporesponder rats than in the hyperresponders. These results could mean that plasma esterase activity is involved in cholesterol metabolism. A low esterase activity may cause an increased susceptibility to dietary cholesterol, whereas induction of plasma esterase activity may be required to compensate for cholesterol load. ing.

In a preliminary attempt to further substantiate our observations we performed a similar experiment with female and male rats of a random-bred Wistar strain. Female rats are known to be more sensitive to dietary cholesterol than their male counterparts (Terpstra et al., 1982). Indeed, Table 2 documents that the female Wistar rats developed very high plasma cholesterol concentrations after cholesterol feeding, whereas the male rats hardly responded. Dietary cholesterol did not influence body weights of the animals (Table 2).

Initial plasma esterase activities, measured with $\beta$-naphthylpropionate, were not significantly different in male and female rats. During the course of the experiment plasma esterase activities decreased somewhat (Table 2). In the male rats cholesterol loading caused a rise in esterase activity of 


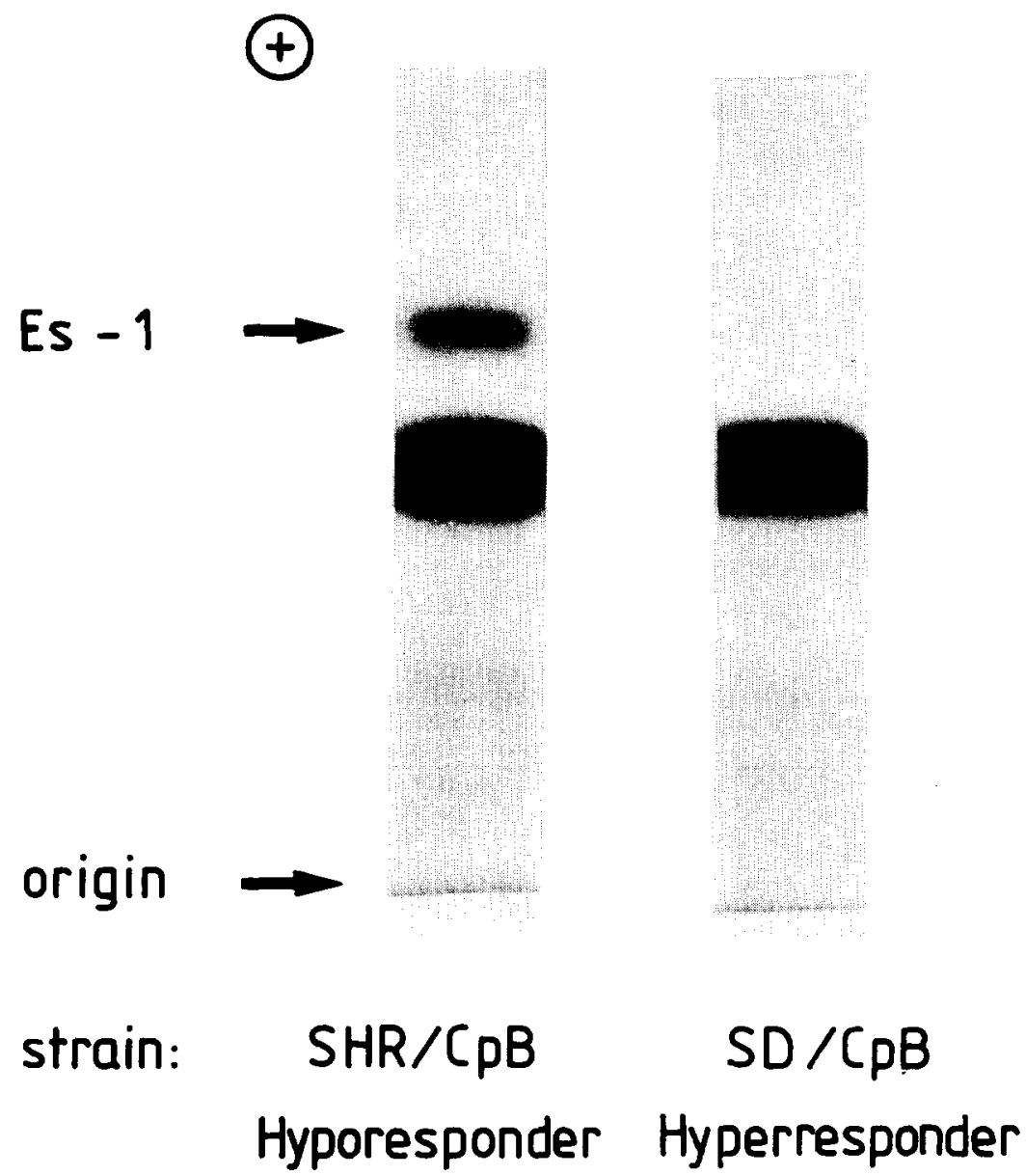

Fig. 1. Electrophoresis on starch gels of esterases in the plasma from two inbred strains of rats on the low-cholesterol control diet. $\beta$-Naphthylpropionate was used as substrate for visualizing enzyme activity.

$0.87 \mu \mathrm{mole} / \mathrm{min} / \mathrm{ml}$ compared with the control animals, and in the fermales the increase was $0.56 \mu \mathrm{mole} / \mathrm{min} / \mathrm{ml}$ (Table 2 ).

Rabbits are very sensitive to dietary cholesterol; the feeding of a diet containing $0.2 \%(w, w)$ cholesterol caused an 8-fold increase in the level of plasma cholesterol within 4 weeks (Table 3 ). Dietary cholesterol did not affect plasma esterase activity measured with either $\alpha$-naphthylacetate or $\beta$-naphthylpropionate as a substrate. On the cholesterol-free diet there was a marked inter-rabbit variation in the plasma esterase activities, the ranges being $0.77-12.00$ and $8.30-19.86 \mu \mathrm{mole} / \mathrm{min} / \mathrm{ml}$ for the substrates $\alpha$-naphthylacetate and $\beta$-naphthylpropionate, respectively. For the individual animals $(n=9)$ there was no correlation between the initial plasma esterase

Table 1. Body weight, plasma cholesterol concentrations and plasma esterase activities in two inbred strains of male rats with low or high plasma cholesterol response to a high-cholesterol diet.

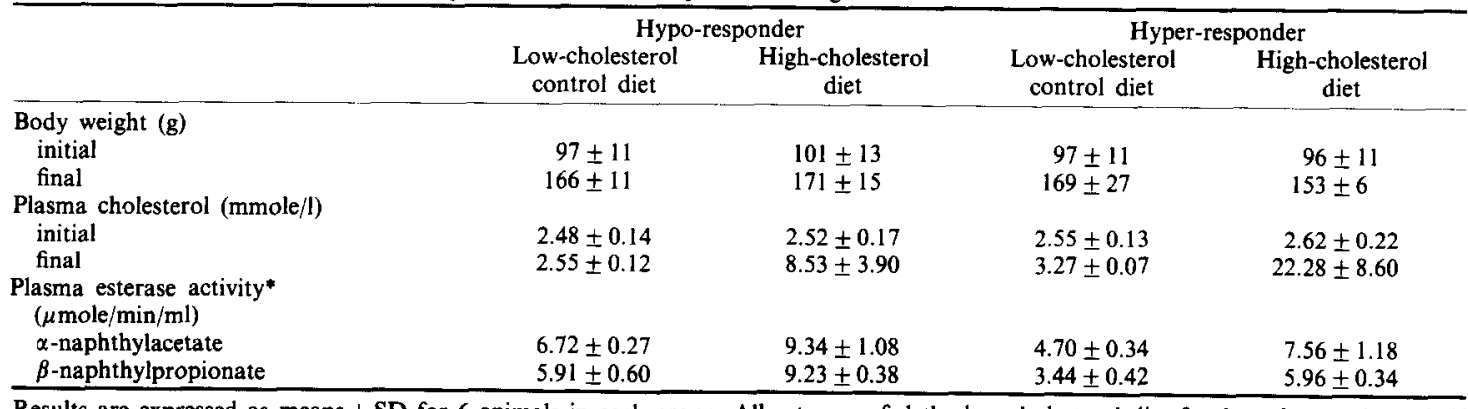

Results are expressed as means \pm SD for 6 animals in each group. All rats were fed the low-cholesterol diet for 3 weeks; on day 0 half of them were then switched to the experimental high-cholesterol diet. Initial and final values refer to days -5 and 23 of the experiment, respectively.

*Esterase activity was measured using the substrates indicated; values refer to day 23 of the experiment. 
Table 2. Body weight, plasma cholesterol concentrations and plasma esterase activities in male and female random-bred Wistar rats ted a low- or high-cholesterol diei

\begin{tabular}{|c|c|c|c|c|}
\hline & & & Fel & ats \\
\hline & $\begin{array}{l}\text { Low-cholesterol } \\
\text { control diet }\end{array}$ & $\begin{array}{c}\text { High-cholesterol } \\
\text { diet }\end{array}$ & $\begin{array}{l}\text { Low-cholesterol } \\
\text { control diet }\end{array}$ & $\begin{array}{c}\text { High-cholesterol } \\
\text { diet }\end{array}$ \\
\hline \multicolumn{5}{|c|}{ Body weight (g) } \\
\hline initial & $295 \pm 40$ & $287 \pm 30$ & $189 \pm 16$ & $193 \pm 20$ \\
\hline final & $304 \pm 43$ & $324 \pm 50$ & $184 \pm 14$ & $189 \pm 20$ \\
\hline \multicolumn{5}{|c|}{ Plasma cholesterol (mmole/1) } \\
\hline initial & $2.10 \pm 0.35$ & $2.10 \pm 0.16$ & $1.77 \pm 0.22$ & $1.70 \pm 0.17$ \\
\hline final & $1.95 \pm 0.18$ & $2.35 \pm 0.41$ & $1.53 \pm 0.29$ & $11.72 \pm 6.57$ \\
\hline \multicolumn{5}{|c|}{$\begin{array}{l}\text { Plasma esterase activity } \\
(\mu \mathrm{mole} / \mathrm{min} / \mathrm{ml})^{*}\end{array}$} \\
\hline initial & $3.88 \pm 0.31$ & $4.07 \pm 0.56$ & $3.85 \pm 0.22$ & $3.67 \pm 0.48$ \\
\hline final & $3.56 \pm 0.61$ & $4.63 \pm 0.55$ & $3.11 \pm 0.14$ & $3.49 \pm 0.50$ \\
\hline change & $-0.32 \pm 0.36$ & $0.55 \pm 0.73$ & $-0.73 \pm 0.08$ & $-0.17 \pm 0.30$ \\
\hline
\end{tabular}

Results are expressed as means \pm SD for 5 animals in each group. All animals were fed the low-cholesterol diet for 10 weeks up until day 0 of the experiment; half of the rats were then switched to the experimental high-cholesterol diet. Initial and final values refer to days -2 and 19 , respectively.

*Measured with $\alpha$-naphthylpropionate as a substrate

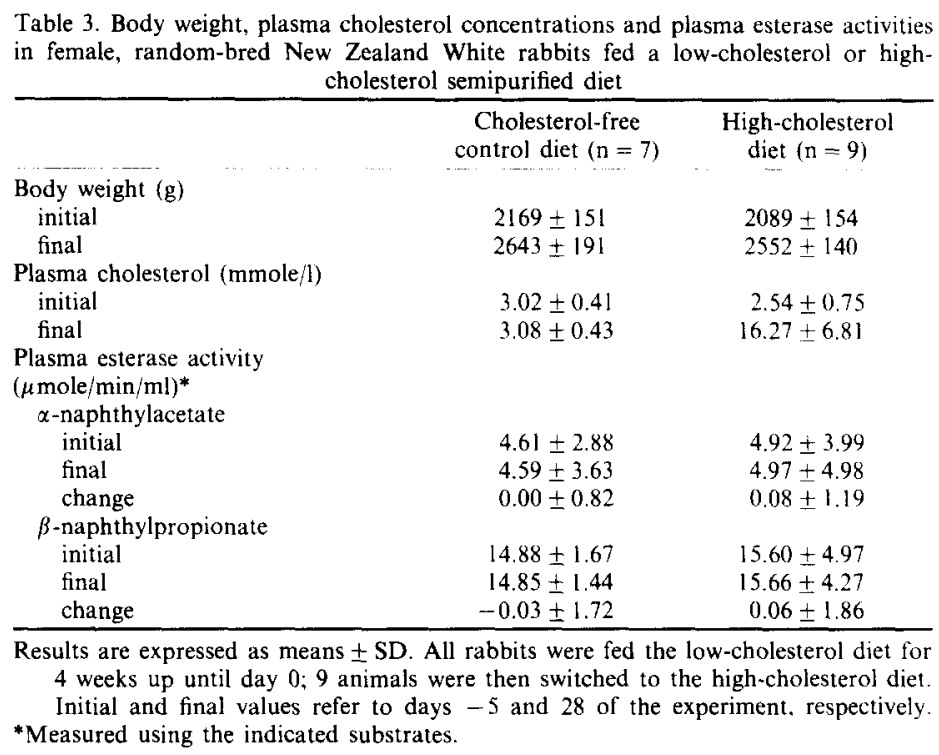

activity and subsequent plasma cholesterol response to cholesterol feeding $(r=-0.23$ for $\alpha$-naphthylacetate and $r=+0.35$ for $\beta$-naphthylpropionate). Likewise there was no correlation $(n=16)$ between the initial plasma esterase activity and the initial plasma cholesterol concentration $(r=-0.14$ for $\alpha$-naphthylacetate and $r=+0.08$ for $\beta$-naphthylpropionate)

In the human volunteers the consumption of six egg yolks per day caused a mean increase of $20 \%$ in the concentration of serum cholesterol (Table 4). The individual response varied considerably, the range being -3 to $+44 \%$. Similar observations were reported earlier (Katan and Beynen, 1983). On the low-cholesterol diet plasma esterase activities varied from 2.81 to $5.87 \mu \mathrm{mole} / \mathrm{min} / \mathrm{ml}$ with $\alpha$-naphthylacetate and from 3.29 to $5.14 \mu \mathrm{mole} / \mathrm{min} / \mathrm{ml}$ with $\beta$-naphthylpropionate. Dietary cholesterol did not significantly affect plasma total esterase activities (Table 4). There was no association between initial plasma esterase activity and serum cholesterol response to egg yolk consumption in man.

\section{DISCUSSION}

Our results strengthen the evidence that one or more of the esterases found in the plasma of rats are involved in the metabolism of cholesterol. In the two inbred strains and also in the random-bred Wistar rats plasma total arylesterase activity was increased after loading with dietary cholesterol.

In the inbred rat strains plasma esterase activity on the low-cholesterol control diet was significantly lower in the hyperresponsive strain than in the hyporesponsive animals. This substantiates earlier reports (Van Zutphen and Fox, 1977; Van Zutphen and Den Bieman, 1981) which suggest that plasma esterase patterns predict the susceptibility to dietary cholesterol. However, the results obtained with the Wistar rats are not completely in line with those found in the inbred strains. The difference in cholesterolemic response to cholesterol feeding between male and female Wistar rats was not associated with different plasma esterase activities on the low-cholesterol control diet. In addition, comparison of Tables 1 and 2 
Table 4. Serum cholesterol concentrations and plasma esterase activities in healthy humans consuming a highcholesterol diet

\begin{tabular}{lr}
\hline $\begin{array}{l}\text { Serum cholesterol (mmole/l) } \\
\text { initial }\end{array}$ & $4.18 \pm 0.63$ \\
final & $5.03 \pm 0.82$ \\
change & $0.85 \pm 0.71$ \\
Plasma esterase activity & \\
( $\mu$ mole/min/ml) & \\
$\alpha$-naphthylacetate & $4.41 \pm 1.14$ \\
initial & $4.59 \pm 0.85$ \\
final & $0.19 \pm 0.44$ \\
change & $4.23 \pm 0.66$ \\
$\beta$-naphthylpropionate & $4.31 \pm 0.74$ \\
initial & $0.08 \pm 0.18$ \\
final & \\
change & \\
\hline Results are expressed as means \pm SD for 5 subjects. The \\
subjects abstained from cholesterol-rich products for \\
10 days (day -9 to 0 ) and then starting with day 1 \\
they added six egg yolks per day to their diet for \\
another 10 days. The initial values in the table are \\
the mean values of days -1 and 0 and the final \\
values are the means of days 9 and 10.
\end{tabular}

shows that on the low-cholesterol diet the inbred hyporesponsive rats have a higher plasma esterase activity with $\beta$-naphthylpropionate as substrate than the male Wistar rats, although the inbred rats were more sensitive to dietary cholesterol. Thus plasma total esterase activity is not a consistent predictor of the susceptibility to dietary cholesterol in all rat strains.

No evidence for a role of plasma arylesterases in cholesterol metabolism was obtained in our studies with random-bred rabbits and in humans. However, it should be realized that human and rabbit plasma contain at least 12 different arylesterases (Pilz, 1964; Pilz et al., 1968), most of them probably not related to cholesterol metabolism. As only one of the esterases (Est-2) in the zymogram of rabbit plasma has been found to predict the serum cholesterol response to dietary cholesterol, it would be desirable to study and measure the plasma esterases separately. Such studies are now in progress, and it is anticipated that they will shed more light on the physiological function(s) of plasma arylesterases.

Acknowledgements - We thank G. Van Tintelen and J. W. M. Haas (Small Animal Centre, Agricultural University, Wageningen) for taking care of the rats and rabbits, $Z$. Kruyswijk for expert analytical assistance, A. van Baaren for the photographic work and L. F. M. van Zutphen and M. G. C. W. den Bieman for helpful discussions. This study was supported by the Netherlands Heart Foundation, grant no. 31.013, and an established investigatorship to M.B.K.

\section{REFERENCES}

Augustinsson K. B. (1958) Electrophoretic separation and classification of blood plasma esterases. Nature, Lond 181, 1786-1789.
Beynen A. C., Boogaard A., Van Laack H. L. J. M., Weinans G. J. B. and Katan M. B. (1983) Abstr. Commun. 15th FEBS Meet., Brussels, p. 173.

Fox R. R. and Van Zutphen L. F. M. (1979) Chromosomal homology of rabbit (Oryctolagus cuniculus) linkage group VI with rodent species. Genetics 93, 183-188.

Katan M. B. and Beynen A. C. (1983) Hyper-response to dietary cholesterol in man. Lancet $\mathbf{i}, 1213$.

Okamoto K., Yamori Y., Ooshima A. and Tanaka T. (1972) Development of substrains in spontaneously hypertensive rats: genealogy, isozymes and effect of hypercholesterolemic diet. Jap. Circ. J. 36, 461-470.

Pilz W. (1961) Methode zur photometrischen Mikrobestimmung kleiner Mengen $\beta$-Naphtol in Gegenwart eines grossen Ueberschusses verschiedener $\beta$-Naphtylester-Emulsionen und deren Verwendung zur Bestimmung der "Aromatischen Esterase" in biologischen Material. Mikrochim. Acta 1, 614-633.

Pilz W. (1964) Untersuchungen über Fermente des menschlichen Blutes, IX. Die Arylesterasen des menschlichen Nabelschnurserums. Hoppe-Seylers Z. physiol. Chem. 338, 238-250.

Pilz W. (1968) Verfolgung der Zusammensetzung des veresterten Fettsäuren im Kaninchenserum während einer experimentellen alimentären Lipämie. Z. klin. Chem. klin. Biochem. 6, 337-343.

Pilz W., Hörlein H. and Stelzl E. (1966) Untersuchungen über Fermente des menschlichen Blutes, XII. Die Rolle einer Arylesterase-Fraktion aus Leber im menschlichen Fettstoffwechsel. Hoppe-Seylers Z. physiol. Chem. 345, 65-79.

Pilz W. and Johann I. (1965) Spezielle analytische Methoden für die Biochemie und physiologische Chemie. I. Mitteilung. Methode zur photometrischen Mikrobestimmung kleiner Mengen $\alpha$-Naphtol in Gegenwart eines grossen Ueberschusses verschiedener $\alpha$-Naphtylesteremulsionen und deren Verwendung in der enzymatischen Analyse. $Z$. analyt. Chem. 210, 113-123.

Pilz W., Stelzl E. and Johann I. (1968) Untersuchungen über esterspaltende Enzyme von Versuchstieren und Methoden zu ihrer routinemässigen Bestimmung, IV. Die Arylesterasen des Kaninchenserums und ihre physiologische Funktion. Enzym. biol. clin. 9, 97-123.

Röschlau P., Bernt W. and Gruber W. (1974) Enzymatische Bestimmung des Gesamt-Cholesterins im Serum. Z. klin. Chem. klin. Biochem. 12, 403-407.

Terpstra A. H. M., Van Tintelen G. and West C. E. (1982) The effect of semipurified diets containing different proportions of either casein or soybean protein on the concentration of cholesterol in whole serum, serum lipoproteins and liver in male and female rates. Atherosclerosis 42, 85-95.

Van Zutphen L. F. M. (1983) Revision of the genetic nomenclature of esterase loci in the rat (Rattus norvegicus). Transpl. Proc. 15, 1687-1688.

Van Zutphen L. F. M. and Den Bieman M. G. C. W. (1981) Cholesterol response in inbred strains of rats, Rattus norvegicus. J. Nutr. 111, 1833-1838.

Van Zutphen L. F. M. and Fox R. R. (1977) Strain differences in response to dietary cholesterol by JAX rabbits: correlation with esterase patterns. Atherosclerosis 28, 435-446.

West C. E., Deuring K., Schutte J. B. and Terpstra A. H. M. (1982) The effect of age on the development of hypercholesterolemia in rabbits fed semipurified diets containing casein. J. Nutr. 112, 1287-1295. 